Table 1. Baseline characteristics

\begin{tabular}{|c|c|c|c|}
\hline & $\begin{array}{l}\text { Originator etanercept } \\
\qquad(n=119)\end{array}$ & $\begin{array}{c}\text { Biosimilar } \\
\text { Etanercept } \\
\quad(n=38)\end{array}$ & $\begin{array}{c}\text { Univariable } \\
\text { Analysis }^{\text {a }} \\
\text { OR( } 95 \% \mathrm{Cl})\end{array}$ \\
\hline Use of previous biologic, $n(\%)$ : & $95(79.8)$ & $16(42.1)$ & $5.4(2.5-11.9)$ \\
\hline Use of steroids, $n(\%)$ : & $45(37.8)$ & $22(57.8)$ & $0.4(0.2-0.9)$ \\
\hline Use of DMARD, n(\%): & 94 (78.9) & $35(92.1)$ & $0.3(0.1-1.1)$ \\
\hline Adverse events ${ }^{\mathrm{b}}, \mathrm{n}(\%)$ : & $4(3.4)$ & $6(15.8)$ & $\begin{array}{c}0.2 \\
(0.04-0.7)\end{array}$ \\
\hline Infections ${ }^{\mathrm{b}}, \mathrm{n}(\%)$ : & $1(0.8)$ & $2(5.3)$ & $0.15(0.1-1.7)$ \\
\hline Allergic reactions ${ }^{b}, n(\%)$ : & $3(2.5)$ & $1(2.6)$ & $0.9(0.1-9.5)$ \\
\hline Severe $^{b}, n(\%):$ & $0(0)$ & $2(5.3)$ & $\mathrm{p}=0.012^{\mathrm{c}}$ \\
\hline
\end{tabular}

${ }^{\mathrm{a}}$ Univariable logistic regression analysis. ${ }^{\mathrm{b}} \mathrm{C}$ umulative at time of analyses, ${ }^{\mathrm{c}} \mathrm{Chi}$-square test.

Conclusion: This preliminary study showed that $A E$ with $B E t$ were more frequent as well as more severe compared to $A E$ presented with OEt in patients with rheumatic diseases using BIOBADAMEX data. Our study suggests that use of BEt and comorbidities are associated with the development of $\mathrm{AE}$. Follow up and inclusion of more participants is going on and will allow us to perform further analyses. References:

[1] Rugo HS et al. Future Oncol. 2019;15(7):777-790

[2] Moots RJ BioDrugs. 2018;32(3):193-199

Disclosure of Interests: Vijaya Rivera Teran: None declared, Marcela Pérez Rodríguez: None declared, Deshire Alpizar-Rodriguez: None declared, Fedra Irazoque-Palazuelos Consultant of: Bristol-Myers Squibb, Janssen, Pfizer Inc, Roche and UCB, Sandra Carrilo: None declared, Sandra Sicsik: None declared, David Vega-Morales: None declared, Dafhne Miranda: None declared, angel castillo: None declared, Julio Cesar Casasola: None declared, Cesar Francisco Pacheco Tena: None declared, José Francisco Moctezuma: None declared, Francisco Aceves: None declared, Aleni Paz: None declared, Sergio Duran Barragan: None declared, Leonor Barile: None declared, Natalia Santana: None declared, Daniel Xavier Xibille Friedmann Consultant of: Lilly, Abbvie, Speakers bureau: Lilly, Abbvie

DOI: 10.1136/annrheumdis-2020-eular.3819

\section{AB1230 $\quad$ PERIPHERAL ARTERY DISEASE AND JOINT PAIN IN TYPE 2 DIABETES PATIENTS, FROM ASSOCIATION TO CAUSATION}

\section{E. Shalaeva ${ }^{1}$, A. Shalaeva ${ }^{1}$, N. Dadabaeva ${ }^{1}$, K. Mirakhmedova ${ }^{1} .{ }^{1}$ Tashkent} Medical Academy, Tashkent, Uzbekistan

Background: Type 2 diabetes mellitus (T2DM) and arthritis are considered two separate conditions. However, inflammation and metabolic changes play a major role in diabetes co-morbidity (1). The pathogenesis of the joint pain and stiffness in diabetes patients is not fully understood. Diabetic osteoarthropathy (neuropathic arthropathy) considers a quite rare condition $(0.1-0.4 \%$ of diabetic patients), involving destructive, lytic joint changes (2). Interestingly, over $52 \%$ of diabetic patients have joint diseases, compare to only $27 \%$ without diabetes; and people with arthritis have over $60 \%$ higher risk of diabetes development (3). Objectives: The purpose of the study was to determine the association between the lesions of low extremity arteries (LEA) and the prevalence of arthritis (joint pain and stiffness) among patients with type 2 diabetes.

Methods: This is the pilot analysis of the musculoskeletal data obtained from the prospective cohort study of patients with diabetes complications 2013-2016 (179 consecutive T2DM pts undergoing transfemoral amputation (TFA) due to gangrene of lower limb $(4,5)$, and 199 patients experienced balloon angioplasty (BA) of the LEA (without gangrenes). The computer tomography angiography was performed, along with clinical, laboratory and instrumental examination. Functional class of joint lesions (hip, knee or foot) was obtained based on self-service and (un)professional activity. Results: All observed patients had diabetic neuropathy. The affected extremity in all the patients undergoing TFA had critical arterial ischemia along with foot gangrene, knee/hip pain, stiffness and rigidity. The second extremity also had stenoses of popliteal, anterior or posterior tibial arteries and the severity of stenoses was positively correlated with the severity of muscle and joints pain $(r=0.771, p<0.001)$

Among 199 patients without gangrene of lower limb, BA was done on superficial femoral artery $46(23.1 \%)$ patients, popliteal in $44(22.1 \%)$, posterior tibial 54 $(27.1 \%)$, arterial tibial 41 (20.6), and peroneal artery 14 (7\%). At least 1 large and 1 small joint was affected per person. The correlation between the prevalence of joint pain/stiffness and peripheral artery stenosis of the same lower extremity in patients without gangrene was significant $r=0.632$, indicating a large positive relationship (approximately $39.9 \%$ of the total variance). A linear regression analysis was conducted to evaluate the association between the severity of artery lesions and the severity of joint functional class, $F(1,198)=57.82, p<0.001, t=$ $7.91, p<0.001$. The $95 \%$ confidence interval for the slope was 0.71 to 1.29 , which did not include the value of zero.
Conclusion: The results show that the more severe the peripheral artery stenosis was the more prevalent join lesions are and worsen the function class. However, more studies are needed.

References:

[1] Shalaeva E.V. et al. Impact of purulent complications and sepsis on car diovascular system in patients with type 2 diabetes. Critical Care 2014 18(Suppl 2):P6; doi:10.1186/cc14009

[2] Kim R.P., et al. Musculoskeletal Complications of Diabetes Mellitus. Clinical Diabetes. 2001, 19 (3) 132-135; DOI: 10.2337/diaclin.19.3.132

[3] Piva S.R., Susko A.M. et al. Links between Osteoarthritis and Diabetes:Implications for Management from a Physical Activity Perspective.

[4] Shalaeva E.V., Saner H, et al. Coronary artery calcium score and coronary computed tomographic angiography for major perioperative cardiovascular complications in symptomatic diabetic patients undergoing trans-femoral amputation. International Journal of Cardiology 221 (2016) 806-811. http:// dx.doi.org/10.1016/j.ijcard.2016.06.165

Disclosure of Interests: None declared

DOI: 10.1136/annrheumdis-2020-eular.3828

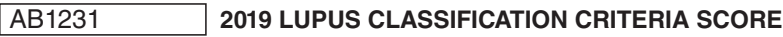
PREDICTS FUTURE LUPUS HOSPITAL ADMISSION

S. Suman ${ }^{1}$, M. Eissa ${ }^{2}$, H. Rogers ${ }^{3}$, A. Lenert ${ }^{4}$, A. Stromberg ${ }^{5}$, W. Roberts ${ }^{3}$.

${ }^{1}$ University of Kentucky, Internal Medicine, Lexington, United States of America;

${ }^{2}$ Cairo University, Cairo, Egypt; ${ }^{3}$ University of Kentucky, Rheumatology, Lexington, United States of America; ${ }^{4}$ University of lowa, Rheumatology, lowa City, United States of America; ${ }^{5}$ University of Kentucky, Statistics, Lexington, United States of America

Background: There are several validated tools to quantitate lupus disease activity, end-organ damage and overall fragility. An algorithm to predict the hospitalization risk in lupus patients was proposed by $\mathrm{Li}$ et $\mathrm{al}^{1}$. That algorithm was able to effectively screen patients at increased risk of hospitalization using EHR information only. Recently, the new 2019 Lupus classification criteria score has been noted to accurately predict 10 year mortality ${ }^{2}$.

Objectives: To test the above 2 algorithms with potential to predict lupus related hospital admissions.

First, we attempted to validate the existing algorithm from the index study of $\mathrm{Li}$ et al to predict lupus hospitalization.

Second, we tested the 2019 lupus clinical classification score for its ability to predict hospitalizations.

Methods: A retrospective chart review was performed using EHR data collected from 2013 to 2018 at University of Kentucky (UK) Medical Center. Inclusion criteria were 18 years or older at first outpatient rheumatology appointment at UK at least 3 outpatient rheumatology visits at UK, and ICD 9/10 code for Lupus. A total of 217 patients met inclusion criteria. Variables similar to the index study were extracted from patients' first outpatient rheumatology visit at UK. Additionally, 2019 Lupus Classification Criteria score was calculated. Patients who were subsequently hospitalized, manual chart review was done to determine if the hospitalization was attributable to lupus or not.

Results: Table 1 shows differences between the variables predicting hospitalization in patients in this study (UK) and the Ohio State University (OSU) cohort from whom the admission predicting algorithm was derived ${ }^{1}$. All the risk factors that were found to predict lupus hospitalization in the index study, failed to achieve a statistical significance in our validation study.

Table 1. Differences in the variables predicting hospitalization between Index and Validation Cohort

\begin{tabular}{lcc}
\hline $\begin{array}{l}\text { Variables predicting Lupus } \\
\text { Hospitalization }\end{array}$ & $\begin{array}{c}\text { Index Study (Ohio State), } \\
\text { \% of patients } \\
(\mathbf{n = 2 2 6})\end{array}$ & $\begin{array}{c}\text { Validation Study } \\
\text { (University of } \\
\text { Kentucky) } \\
\text { \% of patients; (n=217) }\end{array}$ \\
\hline African American & $33 \%$ & $18 \%$ \\
Creatinine $>1.2$ & $17 \%$ & $7 \%$ \\
Hemoglobin $<11 \mathrm{~g} / \mathrm{dl}$ & $79 \%$ & $18 \%$ \\
Platelets $<180 /$ uL & $75 \%$ & $22 \%$ \\
High Risk immunosuppression & $35 \%$ & $9.2 \%$ \\
Missed appointment & $27 \%$ & $25 \%$ \\
\hline
\end{tabular}

There was more success predicting lupus hospitalization using the 2019 lupus classification criteria score (CCS) (Figure 1). A CCS $>=19$ predicted higher risk of lupus related hospitalization vs CCS $<19$ over the ensuing 2 years $(p-0.05)$ 